\title{
Principle of Emulsion PCR and Its Applications in Biotechnology
}

\author{
Changhoon Chai* \\ Department of Applied Animal Science, Kangwon National University, Chuncheon 24341, Korea
}

Received November 20, 2019

Revised December 3, 2019

Accepted December 11, 2019

\section{*Correspondence}

Changhoon Chai

E-mail: chchai@kangwon.ac.kr

ORCID

https://orcid.org/0000-0003-4320-7311

\begin{abstract}
Emulsion polymerase chain reaction (PCR) is performed on compartmentalized DNA, allowing a large number of PCR reactions to be carried out in parallel. Emulsion PCR has unique advantages in DNA amplification. It can be applied in many molecular biological assays, especially those requiring highly sensitive and specific DNA amplification. This review discusses the principle of emulsion PCR and its applications in biotechnology. Related technologies are also discussed.
\end{abstract}

Keywords: DNA enrichment, droplet digital PCR, emulsion PCR, polymerase chain reaction, SELEX

\section{INTRODUCTION}

Polymerase chain reaction (PCR) is an in vitro biological process that mimics in vivo DNA replication, and has led to breakthroughs in biochemistry, biology, and medical science. PCR and associated technologies enable early diagnosis of infectious diseases, rapid prognostic staging for various cancers, sequencing of DNA and RNA, and screening and development of antitumor agents (Viljoen et al., 2005; Hayat, 2008). PCR is expected to continue to play significant roles in advancing bioscience.

The primary aim of PCR and associated technologies is to replicate and amplify target DNA sequences on DNA templates of interest surrounded by nontarget DNA molecules. PCR is carried out via interactions between PCR components, including DNA template, polymerase, primers, nucleotides, and minerals. PCR can identify fewer than ten target DNA sequences among millions of nontarget DNA molecules. However, PCR is hampered by nonspecific reaction between primers and nontarget DNA and primers, resulting in false negatives in infectious dis- ease or cancer testing (Viljoen et al., 2005; Pelt-Verkuil et al., 2008). DNA enrichment, primarily based on PCR, is a necessary step in metagenomic sequencing and systematic evolution of ligands by exponential enrichment (SELEX). Low-frequency DNA variants may be lost during the enrichment of metagenomic specimens and DNA aptamers if a method to replicate DNA sequences independently is not implemented (Fig. 1) (Shanks et al., 2012; Bayat et al., 2018). The occurrence of nonspecific PCR in early stages of the PCR process reduces the amplification of target DNA, which causes false negative results in PCR-based infectious disease and cancer testing, as well as the loss of low-frequency DNA variants.

PCR in aqueous droplets emulsified in the oil phase of water-in-oil emulsions, termed "emulsion PCR," has unique attributes for DNA amplification (KanagalShamanna, 2016). Emulsifying the aqueous PCR phase in the oil phase can compartmentalize individual DNA molecules, creating independent PCR environments (Fig. 1). The sensitivity and specificity of PCR can be significantly improved by performing PCR in water-in-oil emul- 


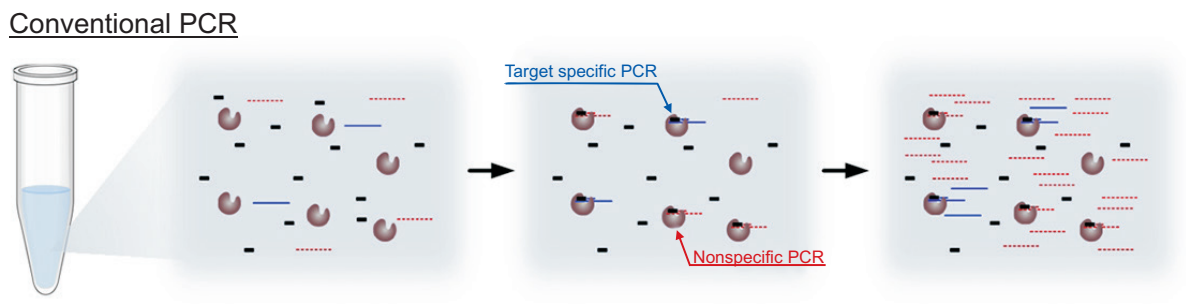

Emulsion PCR

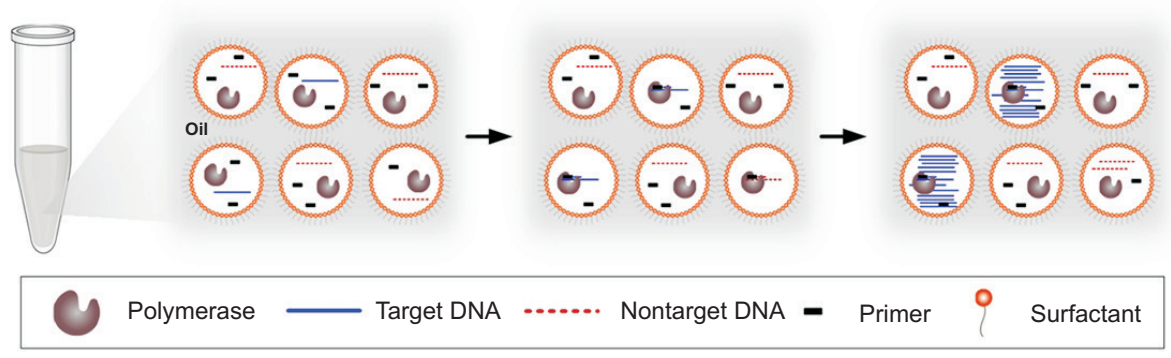

Fig. 1. Schematic illustrates of conventional PCR and emulsion PCR.

sion (Chai and Oh, 2015; Du et al., 2019). The actual number of pathogens present in clinical specimens can be measured using emulsion PCR-based techniques $(\mathrm{Mu}$ et al., 2015). Emulsion PCR-based methods are also used in next-generation sequencing (NGS), metagenomics sequencing, and SELEX to enrich genomic DNA and cDNA libraries while maintaining the same proportions as the original libraries (Shanks et al., 2012; Kanagal-Shamanna, 2016; Bayat et al., 2018). The application of emulsion PCR is expected to support further advances in biological techniques. However, current emulsion PCR-based technologies have several issues that remain to be resolved. For example, emulsion PCR requires the precise optimization of PCR conditions (Kanagal-Shamanna, 2016). Moreover, PCR emulsions can lose their stabilities during temperature fluctuations in PCR.

This review addresses the principle of emulsion PCR and its applications in biotechnology, as well as PCR components and procedures. Technical difficulties associated with emulsion PCR are discussed, and emulsion PCRbased technologies are reviewed.

\section{PRINCIPLE OF EMULSION PCR}

DNA extracted from a clinical specimen for the diagnosis of infection may include only a few viral or bacterial DNA molecules among millions of host DNA molecules (Strain et al., 2013; Kralik and Ricchi, 2017). The size of genomic DNA and cDNA libraries frequently exceeds 1 $\times 10^{6}$ (Ehrlich et al., 2011; Illumina, 2013). The relative abundance of nontarget DNA can cause false negatives in conventional PCR-based diagnostic testing and loss of low-frequency DNA variants in conventional PCR-based DNA enrichment (Fig. 1). Compartmentalizing individual DNA molecules in aqueous PCR droplets emulsified in the oil phase isolates target DNA from nontarget DNA, avoiding some of the challenges associated with conventional PCR-based assays (Fig. 1).

PCR components such as template DNA, polymerase, primers, nucleotides and minerals are soluble in water but not in oil. Water is the continuous phase of the PCR solution, and has different surface energy properties from oil. Thus, oil and water are immiscible. Surfactants can mediate water and oil molecules, allowing water to be dispersed in oil. Tween 80 (polyoxyethylene sorbitan monooleate), Span 80 (sorbitan monooleate), Triton X-100 (polyethylene glycol tert-octylphenyl ether), ABIL EM 90 (cetyl PEG/PPG-10/1 dimethicone; Evonik Industries, Essen, Germany), ABIL WE 09 (blend of polyglyceryl-4 isostearate, cetyl PEG/PPG-10/1 dimethicone, and hexyl laurate; Evonik Industries), and fluorinated silicone are frequently used as surfactants for emulsion PCR (Williams et al., 2006; Heredia and Makarewicz, 2016; Witt et al., 2017). Mineral oil, Tegosoft DEC (diethylhexyl carbonate; Evonik Industries), and silicone oil can be used as the oil phase of emulsion PCR (Pekin et al., 2010; Heredia and Makarewicz, 2016; Witt et al., 2017). Surfactants are generally added to the oil phase. Vortex mixers, magnetic 
stirrers, and microfluidic devices can be used to disperse the aqueous PCR phase in the oil phase (Williams et al., 2006; Zhu et al., 2012; Kanagal-Shamanna, 2016).

Depending on the specific emulsion PCR method, a 20-200 $\mu \mathrm{L}$ volume of the aqueous PCR phase is added to the oil phase to prepare a $100-300 \mu \mathrm{L}$ PCR emulsion (BioRad.; Chai and Oh, 2015; Witt et al., 2017). Vigorous mechanical agitation of PCR emulsions may generate $10^{8}$ $10^{9}$ irregularly sized aqueous PCR droplets with a mean diameter of 4-6 $\mu \mathrm{m}$ (Shao et al., 2011; Witt et al., 2017). Droplet diameter and number can be controlled precisely using microfluidic devices (Byrnes et al., 2018). Microfluidic droplet generators are used in emulsion-based digital PCR, referred to as droplet digital PCR (Strain et al., 2013). Typically, microfluidic droplet generators can generate 1 $\times 10^{5}$ aqueous PCR droplets with a diameter around 120 $\mu \mathrm{m}$ (BioRad.).

The $100 \mu \mathrm{L}$ aqueous PCR phase used for emulsion PCR may include target and nontarget DNA molecules, 1.25 $\mathrm{U}$ polymerase, $0.8 \mu \mathrm{M}$ (80 pmol per reaction) of forward and reverse primers, $0.2 \mathrm{mM}$ dNTPs $(20 \mathrm{nmol}$ per reaction), and other components (Chai and Oh, 2015; Du et al., 2019). For a $94 \mathrm{kD}$ polymerase, a typical unit of polymerase contains about $8 \times 10^{10}$ polymerase molecules (Spangler et al., 2009). Thus, $100 \mu \mathrm{L}$ of the aqueous PCR phase may contain $1 \times 10^{11}$ polymerase molecules, 4.82 $\times 10^{13}$ forward and reverse primers, and $1.20 \times 10^{16}$ dNTPs. Assuming that equally sized aqueous PCR droplets are dispersed in the oil phase, the frequency $(f)$ of aqueous droplets containing $k$ molecules of individual PCR components follows the Poisson distribution (Equation 1) (Swami et al., 2008).

$$
f(k ; \lambda)=\frac{\lambda^{k} \cdot e^{-\lambda}}{k !}
$$

Furthermore, the proportion of the sum of individual PCR components compartmentalized by $k$ units of individual PCR components $\left(N_{p}\right)$ is given by Equation 2:

$$
P(k ; \lambda)=f(k ; \lambda) \cdot N_{e} \cdot k \cdot \frac{1}{N_{p}}=f(k ; \lambda) \cdot \frac{k}{\lambda}
$$

(Equation 2)

where $\lambda$ is calculated by dividing $N_{p}$ by the total number of emulsified aqueous droplets $\left(N_{e}\right), k$ is the estimated number of individual PCR components contained in an emulsified aqueous droplet, and e is the base of the natural logarithm.

The $P$ of polymerase at different $k$ values was calculated using Equation 2 and plotted in Fig. 2A under the assumption of $N_{p}=1 \times 10^{11}$ and $N_{e}=10^{9}$. Given that $\lambda$ is 100 , the $P$ of polymerase at $k=100$ is greater than those of other components (Fig. 2A). The $f$ values of polymerase at $k$ values of 46 and 47 are $6.76 \times 10^{-10}$ and $1.44 \times 10^{-9}$, respectively. As $N_{e}=1 \times 10^{9}$, the formation of aqueous droplets with fewer than 47 polymerases is unlikely. As seen in the $P$ and $f$ of polymerase, all aqueous droplets with $N_{e}=1 \times 10^{9}$ should contain sufficient quantities of primers and dNTPs for PCR. The $N_{e}$ can be varied from 1 $\times 10^{5}$ to $1 \times 10^{9}$ according to the emulsification method (BioRad.; Diehl et al., 2006; Williams et al., 2006). The $P$ of DNA molecules in PCR emulsions is also calculated using Equation 2. If $\leq 1 \times 10^{9}$ DNA molecules are emulsified in $1 \times 10^{9}$ aqueous droplets, no aqueous droplet with more than 11 DNA molecules is likely to be generated (Fig. 2B). The maximum $k$ of DNA molecules at $N_{e}=1 \times 10^{9}$ and $N_{p}=1 \times 10^{8}, 1 \times 10^{7}, 1 \times 10^{6}, 1 \times 10^{5}, 1 \times 10^{4}, 1$ $\times 10^{3}, 1 \times 10^{2}$, and $1 \times 10^{1}$ are $6,3,2,2,2,1,1$, and 1 , respectively (Fig. 2B). Assuming that $\leq 10^{5}$ DNA molecules are introduced to $10^{5}$ aqueous droplets, the maximum $k$ of DNA molecules in an aqueous droplet at $N_{p}=1 \times 10^{5}$, $1 \times 10^{4}, 1 \times 10^{3}, 1 \times 10^{2}$, and $1 \times 10^{1}$ are $8,3,2,1$, and 1, respectively (Fig. 2C). Although aqueous droplets in PCR emulsions may contain more than one DNA molecule at $N_{e}=1 \times 10^{9}$ and $N_{p}=1 \times 10^{8}, 1 \times 10^{7}, 1 \times 10^{6}, 1 \times$ $10^{5}$, and $1 \times 10^{4}$, as well as $N_{e}=1 \times 10^{5}$ and $N_{p}=1 \times 10^{5}$, $1 \times 10^{4}$, and $1 \times 10^{3}$, highly sensitive and specific PCR in aqueous droplets can be achieved due to the specificity of PCR primers against their target DNA sequences.

\section{METHODS OF EMULSION PCR}

Emulsion PCR is performed via aqueous droplet generation, PCR amplification inside aqueous droplets, and detection of PCR inside aqueous droplets. Emulsion PCR can be categorized into conventional and fluorescencebased methods. Conventional emulsion PCR includes an emulsion-breaking step to collect enriched DNA molecules, and conventional PCR is subsequently performed with collected DNA molecules from the emulsion. Fluorescence-based emulsion PCR uses fluorescent dyes to 


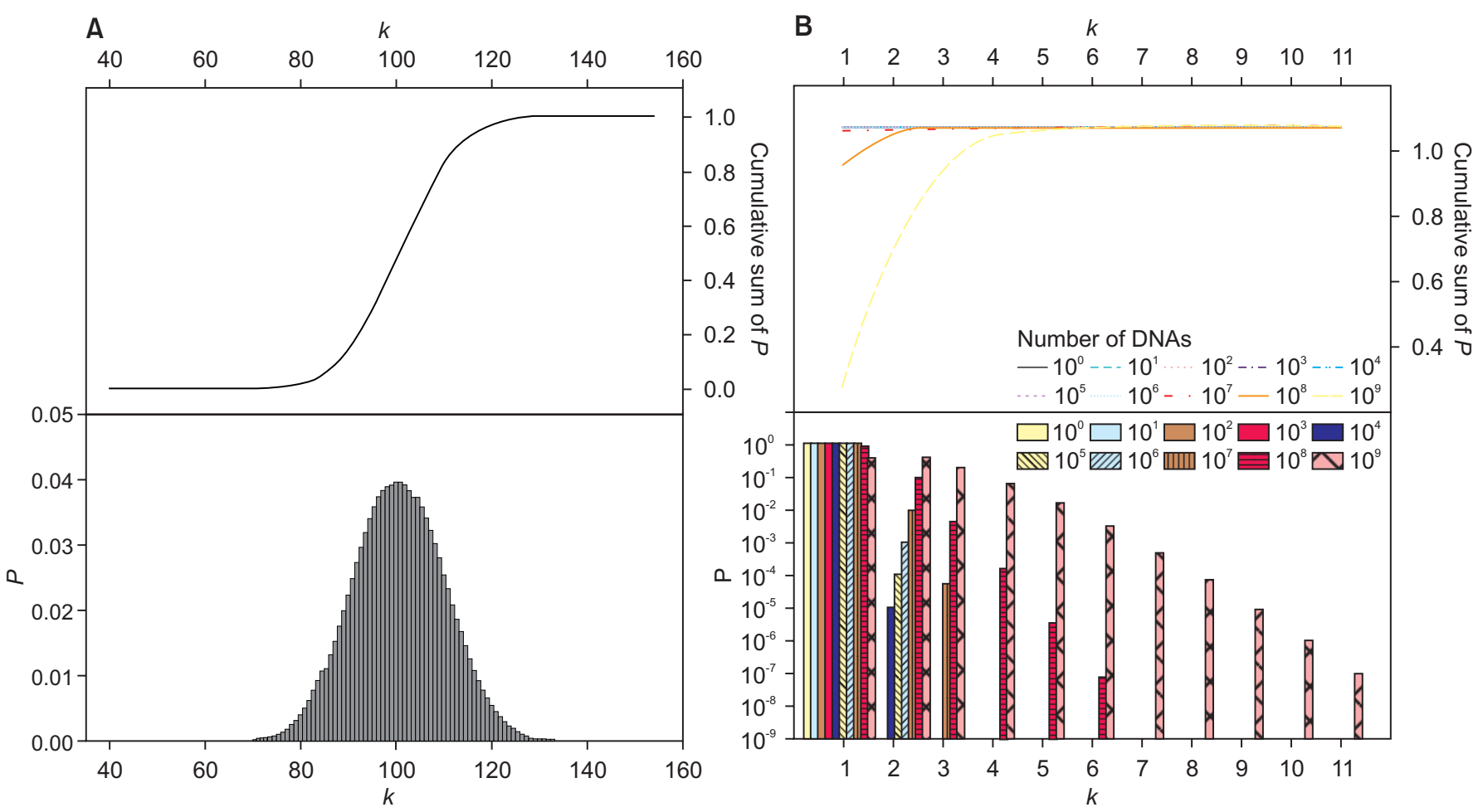

C $k$

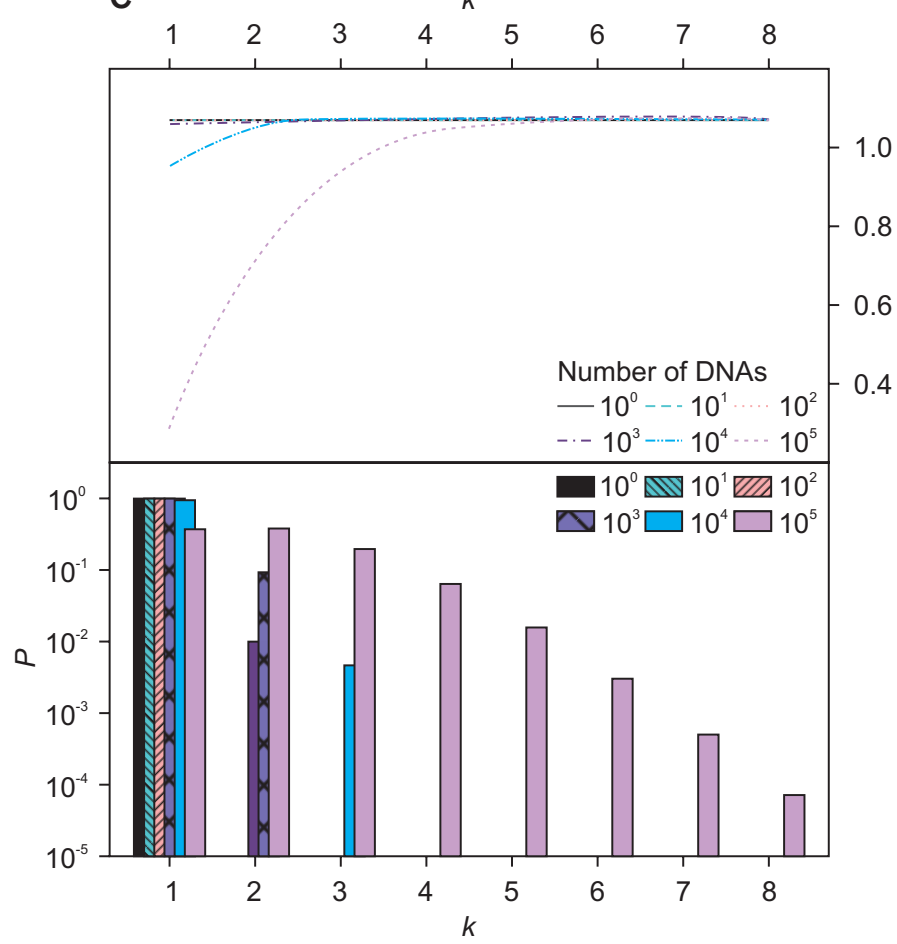

directly detect DNA amplification inside droplets.

Conventional emulsion PCR methods generally use mechanical agitation techniques such as stirring and vortexing to emulsify PCR components. PCR emulsions can be prepared using two different formulas. Williams
Fig. 2. The proportion $(P)$ of the sum of Taq polymerase and DNA molecules compartmentalized by $k$ to their total molecule number $\left(N_{p}\right)$ based on the Poisson distribution equation. (A) The $P$ of Taq polymerase by $k$ (bottom) and the cumulative sum of $P$ (top) under $N_{p}=1 \times 10^{11}$ and number of emulsified aqueous droplets in PCR emulsions $\left(N_{e}\right)=1 \times 10^{9}$. (B) The $P$ of DNA molecules by $k$ (bottom) and cumulative sum of $P$ (top) under $N_{p}=10^{0}-10^{9}$ and $N_{e}=1 \times 10^{9}$. (C) The $P$ of DNA molecules by $k$ (bottom) and cumulative sum of $P$ (top) under $N_{p}=1 \times 10^{0}-$ $1 \times 10^{5}$ and $N_{e}=1 \times 10^{5}$.

et al. reported an emulsion PCR formulation based on a mixture of $200 \mu \mathrm{L}$ of aqueous PCR phase (containing PCR components) and $400 \mu \mathrm{L}$ of mineral oil supplemented with $4.5 \%$ Span $80,0.4 \%$ Tween 80 , and $0.05 \%$ Triton X-100 (Williams et al., 2006). Diehl et al. and Schütze 
et al. used a formulation composed of $150 \mu \mathrm{L}$ of aqueous PCR phase and $600 \mu \mathrm{L}$ of oil phase composed of $73 \%$ emollient Tegosoft DEC, 20\% mineral oil, and 7\% ABIL WE 09 (Diehl et al., 2006; Schütze et al., 2011). In both formulas, bovine serum albumin is included in the aqueous PCR phase to prevent denaturation of the polymerase at the water-oil interface (Diehl et al., 2006; Williams et al., 2006). The $N_{e}$ for both conventional emulsion PCR methods is approximately $1 \times 10^{9}$ (Williams et al., 2006; Witt et al., 2017). The concentration of dNTP in the aqueous PCR phase for both methods is $0.2 \mathrm{mM} \mathrm{(30} \mathrm{and} 40 \mathrm{nmol}$ per 150 and $200 \mu \mathrm{L}$ PCR reaction, respectively). Under these conditions, the average $k$ of dNTPs is $1.81-3.13 \times$ $10^{7}$. If a single DNA molecule is compartmentalized in an aqueous droplet with $1.81-3.13 \times 10^{7}$ dNTPs and PCR is designed to amplify a 500-bp fragment, dNTPs should be used up after the production of about $3.61-6.26 \times$ $10^{4}$ DNA amplicons, corresponding to approximately 16 PCR cycles. In addition, $3.61-6.26 \times 10^{4}$ DNA amplicons are not sufficient for identification by electrophoresis; hence, conventional PCR should be used to amplify enriched target DNA molecules after emulsion PCR. DNA in the emulsion may be extracted by adding organic solvents (diethyl ether, ethyl acetate, and isobutanol), followed by aqueous PCR phase recovery by centrifugation and DNA purification using a commercial kit (Witt et al., 2017). DNA recovery from PCR emulsions is quite tedious and complicated. Thus, a simple and easy method of DNA recovery from PCR emulsions is required for further development of conventional emulsion PCR techniques. Since they generate a large number $\left(\sim 1 \times 10^{9}\right)$ of aqueous PCR droplets, conventional emulsion PCR methods are suitable for enriching low-frequency target DNA molecules in up to $1 \times 10^{9}$ nontarget DNA molecules (Fig. 2B).

Fluorescence-based emulsion PCR methods include fluorescent dyes, such as SYBR green and EvaGreen, or fluorescence probes such as TaqMan probes, in the aqueous PCR phase to generate fluorescence during PCR inside aqueous droplets (Yang et al., 2014; Martinez-Hernandez et al., 2019; Zhang et al., 2019). Because fluorescencebased emulsion PCR methods are capable of visualizing DNA amplification inside individual aqueous droplets, they have been applied to digital PCR techniques (Strain et al., 2013). Fluorescence-based emulsion PCR methods generally use microfluidic devices to generate aqueous droplets (BioRad.). Microfluidic and fluorescence-based emulsion PCR platforms are now commercially available, such as the QX200 Droplet Digital PCR System (Bio-Rad, Hercules, CA, USA). This commercialized system uses silicone oil and fluorinated oil for the oil phase, as well as surfactants. It is operated with $\sim 1 \times 10^{5}$ aqueous PCR droplets with $120 \mu \mathrm{m}$ in diameter that are generated with $20 \mu \mathrm{L}$ of aqueous PCR phase and $70 \mu \mathrm{L}$ of oil phase by a microfluidic droplet generator (BioRad.). The final concentration of dNTPs recommended by the droplet digital PCR system's manufacturer is $0.8 \mathrm{mM}$. Under these conditions, the average $k$ of dNTPs at $N_{e}=1 \times 10^{5}$ is $9.64 \times$ $10^{10}$. Assuming that the DNA amplicon is $500 \mathrm{bp}$, the copy number of DNA amplified with $9.64 \times 10$ dNTPs may not exceed $1.93 \times 10^{8}$ and dNTPs may be used up after 28 PCR cycles. However, the manufacturer of the commercial droplet digital PCR system recommends 40 PCR cycles (BioRad.). Fluorescence-based emulsion PCR methods can quantify even a single target DNA molecule mixed with nontarget DNA molecules (Fig. 2C). They may be appropriate for early diagnosis of viral and bacterial infection.

Conventional and fluorescence-based emulsion PCR methods may be performed under regular PCR conditions but with a greater number of cycles. The viscosity of the oil phase changes with temperature. As temperature increases and decreases during PCR, aqueous PCR droplets circulate, collide, and are prone to coalesce in PCR emulsions (Holtze et al., 2008). The coalescence of aqueous PCR droplets may compromise the Poisson distribution and emulsion PCR performance. The coalescence of aqueous PCR droplets during PCR can be minimized if PCR is carried out isothermally. The use of loop-mediated isothermal DNA amplification in fluorescence-based emulsion PCR methods confers superior amplification efficiency and specificity compared with previous methods (Ma et al., 2018). Moreover, since isothermal DNA amplification-based methods do not require a thermal cycler, they may support the development of simple, miniaturized fluorescence-based emulsion PCR systems.

\section{APPLICATIONS OF EMULSION PCR IN BIOTECHNOLOGY}

Metagenomic NGS is used to investigate the taxonomic composition and genetic content of microorganisms in foods, as well as biological and environmental specimens (Quince et al., 2017; Chiu and Miller, 2019). DNA 
variants may be present in microbial DNA specimens at frequencies too low for NGS. Thus, DNA variants in some specimens must be enriched before sequencing. DNA enrichment using conventional PCR is biased towards the amplification of short- or high-frequency DNA variants and DNA sequences that match the polymerase sequence preference (Blind and Blank, 2015; Yufa et al., 2015). For example, assuming that a specific DNA variant is 1.5 times as abundant as another DNA, it will become $1.5^{30}=191,751.1$ times as abundant after 30 PCR cycles. DNA enrichment for metagenomics sequencing should amplify DNA molecules in the same proportions as in the original microbial DNA specimen, which can be achieved via emulsion PCR (Kihana et al., 2013). Emulsion PCR is therefore included in many NGS methods for unbiased DNA enrichment (Linderholm, 2019).

Emulsion PCR is also the standard method for enrichment of DNA or cDNA aptamer candidates during SELEX (Witt et al., 2017). SELEX is a molecular biological technique for selecting DNA or cDNA aptamers of interest from an aptamer library comprising $\sim 1 \times 10^{15}$ sequences (Tuerk and Gold, 1990). Due to the enormous size of the aptamer library, the selection and enrichment of aptamer candidates should be repeated until the aptamer of interest is identified. In conventional PCR, low-frequency DNA or cDNA variants can be lost during enrichment. Enrichment of DNA aptamer candidates using emulsion PCR can prevent the production of PCR byproducts and avoid the loss of low-frequency aptamer candidates (Shao et al., 2011).

Droplet digital PCR has attracted great interest for the early diagnosis of infectious diseases and rapid prognostic staging of cancers. For instance, a droplet digital PCRbased assay capable of quantifying $1-10^{4} \mathrm{E}$. coli in $1 \mathrm{~mL}$ of blood has been reported (Kang et al., 2014). Droplet digital PCR-associated diagnostic methods for viruses are more sensitive than other viral diagnosis methods (Strain et al., 2013; Myerski et al., 2019), and may be able to measure a single virus in a clinical specimen (Mu et al., 2015).

The quantity of circulating tumor DNA can be the basis for cancer prognosis and recurrence prediction (Perkins et al., 2017), and is also used to investigate the response and resistance to therapeutic agents (Perkins et al., 2017). However, it is difficult to measure circulating tumor DNA using current molecular biological methods, such as quantitative PCR, because of background DNA from nor- mal cells (Perkins et al., 2017). A recent study showed that a droplet digital PCR-based assay exhibited 13\% greater sensitivity than NGS-based assays for KRAS mutations (Demuth et al., 2018). Droplet digital PCR-based circulating tumor DNA assays may be a powerful approach for evaluating cancer patients' prognosis and response to treatment.

\section{CONFLICTS OF INTEREST}

No potential conflict of interest relevant to this article was reported.

\section{ACKNOWLEDGEMENTS}

This study was supported by a grant from the National Research Foundation of Korea (NRF-2013R1A1A2060458), funded by the Korean government.

\section{AUTHOR'S AFFILIATION, POSITION AND ORCID NO.}

\author{
C Chai, Kangwon Nat'l Univ., Assistant Professor, \\ https://orcid.org/0000-0003-4320-7311
}

\section{REFERENCES}

Bayat P, Nosrati R, Alibolandi M, Rafatpanah H, Abnous K, Khedri M, Ramezani M. 2018. SELEX methods on the road to protein targeting with nucleic acid aptamers. Biochimie. 154:132-155.

BioRad. QX200 droplet digital PCR system. https://www. bio-rad.com/ko-kr/product/qx200-droplet-digital-pcrsystem?ID=MPOQQE4VY. Accessed Oct. 312019.

Blind M and Blank M. 2015. Aptamer selection technology and recent advances. Mol Ther Nucleic Acids. 4:e223.

Byrnes SA, Chang TC, Huynh T, Astashkina A, Weigl BH, Nichols KP. 2018. Simple polydisperse droplet emulsion polymerase chain reaction with statistical volumetric correction compared with microfluidic droplet digital polymerase chain reaction. Anal Chem. 90:9374-9380.

Chai C and Oh S-W. 2015. Emulsion PCR to improve sensitivity of PCR-based E. coli O157:H7 ATCC 35150 detection. Food Sci Biotechnol. 24:1559-1563.

Chiu CY and Miller SA. 2019. Clinical metagenomics. Nat Rev Genet. 20:341-355.

Demuth C, Spindler K-LG, Johansen JS, Pallisgaard N, Nielsen D, Hogdall E, Vittrup B, Sorensen BS. 2018. Measuring KRAS mutations in circulating tumor DNA by droplet digital PCR 
and next-generation sequencing. Transl Oncol. 11:12201224.

Diehl F, Li M, He Y, Kinzler KW, Vogelstein B, Dressman D. 2006. BEAMing: single-molecule PCR on microparticles in water-in-oil emulsions. Nat Methods. 3:551-559.

Du Y, Zhao X, Zhao B, Xu Y, Shi W, Ren F, Wu Y, Hu R, Fan X, Zhang Q, Zhang X, Zhang W, Wu W, Shi B, Zhao H, Zhao K. 2019. A novel emulsion PCR method coupled with fluorescence spectrophotometry for simultaneous qualitative, quantitative and high-throughput detection of multiple DNA targets. Sci Rep. 9:184.

Ehrlich DJ, McKenna BK, Evans JG, Belkina AC, Denis GV, Sherr DH, Cheung MC. 2011. Parallel imaging microfluidic cytometer. In: Z. Darzynkiewicz, E. Holden, A. Orfao, W. Telford and D. Wlodkowic (eds.) Methods in cell biology. Academic Press. p 49-75.

Hayat MA. 2008. Methods of cancer diagnosis, Therapy and prognosis: breast carcinoma. Springer, Heidelberg.

Heredia NJ and Makarewicz AJ. 2016. Methods and compositions for using oils for analysis and detection of molecules. US9427737B2. U.S. Patent and Trademark Office.

Holtze C, Rowat AC, Agresti JJ, Hutchison JB, Angilè FE, Schmitz CHJ, Köster S, Duan H, Humphry KJ, Scanga RA, Johnson JS, Pisignano D, Weitz DA. 2008. Biocompatible surfactants for water-in-fluorocarbon emulsions. Lab Chip. 8:1632-1639.

Illumina. 2013. 16s metagenomic sequencing library preparation. https://support.illumina.com/documents/documentation/chemistry_documentation/16s/16s-metagenomiclibrary-prep-guide-15044223-b.pdf. Accessed 2019-10-17.

Kanagal-Shamanna R. 2016. Emulsion PCR: Techniques and applications. In: R. Luthra, R. R. Singh and K. P. Patel (eds.) Clinical Applications of PCR. Springer. p 33-42.

Kang D-K, Ali MM, Zhang K, Huang SS, Peterson E, Digman MA, Gratton E, Zhao W. 2014. Rapid detection of single bacteria in unprocessed blood using integrated comprehensive droplet digital detection. Nat Commun. 5:5427.

Kihana M, Mizuno F, Sawafuji R, Wang L, Ueda S. 2013. Emulsion PCR-coupled target enrichment: An effective fishing method for high-throughput sequencing of poorly preserved ancient DNA. Gene. 528:347-351.

Kralik P and Ricchi M. 2017. A basic guide to real time pcr in microbial diagnostics: Definitions, parameters, and everything. Front Microbiol. 8.

Linderholm AE. 2019. DNA: Next generation sequencing. In: S. L. L. Varela (ed.) The encyclopedia of archaeological sciences. Wiley. p 1-3.

Ma Y-D, Luo K, Chang W-H, Lee G-B. 2018. A microfluidic chip capable of generating and trapping emulsion droplets for digital loop-mediated isothermal amplification analysis. Lab Chip. 18:296-303.

Martinez-Hernandez F, Garcia-Heredia I, Lluesma Gomez M, Maestre-Carballa L, Martínez Martínez J, Martinez-Garcia M. 2019. Droplet digital PCR for estimating absolute abundances of widespread pelagibacter viruses. Front Microbiol.
10.

Mu D, Yan L, Tang H, Liao Y. 2015. A sensitive and accurate quantification method for the detection of hepatitis B virus covalently closed circular DNA by the application of a droplet digital polymerase chain reaction amplification system. Biotechnol Lett. 37:2063-2073.

Myerski A, Siegel A, Engstrom J, McGowan I, Brand RM. 2019. The use of droplet digital PCR to quantify HIV-1 replication in the colorectal explant model. AIDS Res Hum Retroviruses. 35:326-334.

Pekin D, Skhiri Y, Baret J, Le Corre D, Mazutis L, Salem CB, Griffiths A, Laurent-Puig P, Taly V. 2010. Droplet-based microfluidics for the quantitative detection of rare mutations. In: Proceedings of MicroTAS. p 58-60.

Pelt-Verkuil Ev, Belkum Av, Hays JP. 2008. Principles and technical aspects of PCR amplification. Springer, Heidelberg.

Perkins G, Lu H, Garlan F, Taly V. 2017. Droplet-based digital PCR: Application in cancer research. In: G. S. Makowski (ed.) Advances in Clinical Chemistry. Elsevier. p 43-91.

Quince C, Walker AW, Simpson JT, Loman NJ, Segata N. 2017. Shotgun metagenomics, from sampling to analysis. Nat Biotechnol. 35:833.

Schütze T, Rubelt F, Repkow J, Greiner N, Erdmann VA, Lehrach H, Konthur Z, Glökler J. 2011. A streamlined protocol for emulsion polymerase chain reaction and subsequent purification. Anal Biochem. 410:155-157.

Shanks ME, Downes SM, Copley RR, Lise S, Broxholme J, Hudspith KAZ, Kwasniewska A, Davies WIL, Hankins MW, Packham ER, Clouston P, Seller A, Wilkie AOM, Taylor JC, Ragoussis J, Németh AH. 2012. Next-generation sequencing (NGS) as a diagnostic tool for retinal degeneration reveals a much higher detection rate in early-onset disease. Europ J Hum Genet. 21:274.

Shao K, Ding W, Wang F, Li H, Ma D, Wang H. 2011. Emulsion PCR: A high efficient way of PCR amplification of random DNA libraries in aptamer selection. PLoS One. 6:e24910.

Spangler R, Goddard NL, Thaler DS. 2009. Optimizing Taq polymerase concentration for improved signal-to-noise in the broad range detection of low abundance bacteria. PLoS One. 4:e7010.

Strain MC, Lada SM, Luong T, Rought SE, Gianella S, Terry VH, Spina CA, Woelk CH, Richman DD. 2013. Highly precise measurement of HIV DNA by droplet digital PCR. PLoS One. 8:e55943.

Swami A, Espinosa G, Guillot S, Raspaud E, Boué F, Langevin D. 2008. Confinement of DNA in water-in-oil microemulsions. Langmuir. 24:11828-11833.

Tuerk C and Gold L. 1990. Systematic evolution of ligands by exponential enrichment: RNA ligands to bacteriophage T4 DNA polymerase. Science. 249:505-510.

Viljoen GJ, Nel LH, Crowther JR. 2005. Molecular diagnostic PCR handbook. Springer, Heidelberg.

Williams R, Peisajovich SG, Miller OJ, Magdassi S, Tawfik DS, Griffiths AD. 2006. Amplification of complex gene libraries by emulsion PCR. Nat Methods. 3:545-550. 
Witt M, Phung NL, Stalke A, Walter J-G, Stahl F, von Neuhoff N, Scheper T. 2017. Comparing two conventional methods of emulsion PCR and optimizing of Tegosoft-based emulsion PCR. Eng Life Sci. 17:953-958.

Yang R, Paparini A, Monis P, Ryan U. 2014. Comparison of nextgeneration droplet digital PCR (ddPCR) with quantitative PCR (qPCR) for enumeration of Cryptosporidium oocysts in faecal samples. Int J Parasitol. 44:1105-1113.

Yufa R, Krylova SM, Bruce C, Bagg EA, Schofield CJ, Krylov SN. 2015. Emulsion PCR significantly improves nonequilibrium capillary electrophoresis of equilibrium mixtures-based ap- tamer selection: Allowing for efficient and rapid selection of aptamer to unmodified ABH2 protein. Anal Chem. 87:14111419.

Zhang L, Jing X, Chen W, Bai J, Vasseur L, He W, You M. 2019. Selection of reference genes for expression analysis of plantderived microRNAs in Plutella xylostella using qRT-PCR and ddPCR. PLoS One. 14:e0220475.

Zhu Z, Jenkins G, Zhang W, Zhang M, Guan Z, Yang CJ. 2012. Single-molecule emulsion PCR in microfluidic droplets. Anal Bioanal Chem. 403:2127-2143. 